\title{
A CRITICAL RACE THEORY ANALYSIS OF PUBLIC PARK FEATURES IN LATINO IMMIGRANT NEIGHBORHOODS
}

\author{
Jennifer J. García \\ Division of Health Sciences, California State University, Dominguez Hills
}

Gilbert C. Gee

Department of Community Health Sciences, University of California, Los Angeles

Malia Jones

Applied Population Laboratory, Department of Community and Environmental Sociology, University of Wisconsin-Madison

\begin{abstract}
The present-day location of public parks should be understood in the proper social and historical context of residential segregation and urban development. In Los Angeles, discriminatory practices such as restrictive covenants were used not only for housing, but also to maintain segregated recreational spaces. In addition, the economic changes that came as a result of White flight, suburbanization, and inner city job loss brought with it a reduction in local government resources, including funds for public parks. These changes to the urban landscape disproportionately impacted low-income immigrant communities, including Latino neighborhoods. Health disparities researchers are concerned with the inequitable distribution of parks and recreation facilities because it may contribute to disparities in physical inactivity and obesity, health risks that disproportionately impact Latinos. However, much of the literature investigating disparities in the built environment fails to include a racial analysis. The current study uses a Critical Race Theory framework to examine disparities in park availability in Los Angeles. We used a unique park dataset created in ArcGIS to carry out a county-wide assessment of the availability of park features at the neighborhood level. Data come from two sources, the Los Angeles County Location Management System, which includes information on specific park features (e.g., swimming pools, parks and gardens, recreation centers) and the American Community Survey, which includes neighborhood-level sociodemographic information. A zero-inflated negative binomial regression model was used to test whether Latino immigrant neighborhood characteristics are associated with the availability of park features in Los Angeles. Results indicate that Latino immigrant neighborhoods have limited park availability. The discussion situates these findings of inequitable distribution of park resources in the appropriate social and historical context of Latinos living in Los Angeles.
\end{abstract}

Keywords: Critical Race Theory, Parks, Neighborhoods, Latinos, Los Angeles

Du Bois Review, 13:2 (2016) 397-411.

(C) 2016 Hutchins Center for African and African American Research 1742-058X/16 \$15.00

doi:10.1017/S1742058X16000187 


\section{INTRODUCTION}

Contemporary health disparities research seldom examines the social contexts in which disparate neighborhood environments develop, and instead provides de-historicized analysis about current health problems (Chowkwanyun 2011; Ford and Airhihenbuwa, 2010; White 2011). To address these shortcomings, some public health researchers suggest applying Critical Race Theory (CRT), a race-equity methodology that emphasizes inclusion of historicized and contextualized analysis, and prioritizes questions of race and racism (Ford and Airhihenbuwa, 2010; Graham et al., 2011).

Studies of environmental racism typically focus on exposure to harmful features of the environment such as toxic waste facilities and their disproportionate presence in low-income and minority communities (Boone et al., 2009). An alternative approach is to consider the availability and distribution of environmental resources. In the same way that the presence of dis-amenities is harmful to health, a lack of health-promoting amenities can also harm health (Boone et al., 2009; Park and Pellow, 2011). For example, although public parks are recognized as important health-promoting resources in urban environments, there are considerable disparities in the availability of parks, recreational facilities, and open space for residents of many metropolitan areas (Abercrombie et al., 2008; Boone et al., 2009; Duncan et al., 2012; Harnik et al., 2012; Moore et al., 2008; RWJF 2013). Low-income and minority communities in Los Angeles have less access to both parks (Sister et al., 2010; Wolch et al., 2005) and recreation classes (Dahmann et al., 2010) than White neighborhoods. Consistent with the general finding that structural deprivation in non-White neighborhoods can contribute to poor health (Gee and Payne-Sturges, 2004; Williams and Collins, 2001), there is evidence that living in a Latino-concentrated neighborhood is associated with increased obesity risk (Corral et al., 2013; Do et al., 2007; Park et al., 2008; Wen and Maloney, 2011). One explanation for these findings is that Latino concentrated neighborhoods lack the recreational resources that support active lifestyles, such as public parks (Day 2006; Sallis and Glanz, 2009).

The present-day location of recreational resources should be understood in the proper social and historical context of twentieth-century urban development (Boone et al., 2009; Byrne and Wolch, 2009; Joassart-Marcelli 2010; Pulido 2000). Racially restrictive covenants and zoning laws were used to maintain segregated recreational spaces such as parks, swimming pools, and beaches (Culver 2010; García and Flores, 2005). Further, economic changes that came as a result of White flight, suburbanization, and inner city job loss during the mid-twentieth century brought with it a reduction in local government resources, including funds for park provision, programming, and maintenance (Joassart-Marcelli et al., 2005). Lowincome communities of color were disproportionately harmed by these changes to the urban landscape (Culver 2010; García and Flores, 2005). The purpose of this study is to understand current disparities in the location of parks and recreation resources for Latinos in Los Angeles within a broader historicized context, using a CRT framework.

\section{Critical Race Theory}

Critical Race Theory is a movement rooted in legal scholarship that is based on the idea that racism is an ordinary and entrenched feature of American life (Delgado and Stefancic, 2012; Ford and Airhihenbuwa, 2010). Furthermore, racism is structural 
and not limited to individual, overt acts (Bonilla-Silva 1997). Racism permeates our interpersonal interactions, institutional policies, and societal ideologies (Delgado and Stefancic, 2000). Research and data must be understood in their appropriate social contexts in order to examine the sociopolitical and historical dimensions of inequality (Graham et al., 2011). CRT scholars interrogate the central role that race and racism play in creating and maintaining a racialized hierarchy, in which Whites occupy a privileged social location and people of color are marginalized (Crenshaw 1995). CRT offers scholars concerned with health equity a critical framework from which to challenge common interpretations of racial disparities in health (Ford and Airhihenbuwa, 2010; Graham et al., 2011). In this paper we focus on White privilege, a concept central to CRT, to investigate the relationship between race, Latino neighborhoods, and public parks in Los Angeles.

Laura Pulido (2000) describes White privilege as "the hegemonic structures, practices, and ideologies that reproduce Whites' privileged status" (p.15). An important feature of White privilege is that the social advantages and material benefits of being White come at the expense of people of color (Pulido 2000). White environmental privilege is exemplified in the history of urban development (Park and Pellow, 2011; Taylor 2009) as White interests were routinely prioritized over those of non-Whites in the design and planning of parks (Hise and Deverell, 2000). The history of parks and recreation in Los Angeles is directly linked to the region's reputation as a place of leisure, sunshine, and healthy living (Culver 2010; Hise and Deverell, 2000). As early as the late 1800s, local boosters and land developers promoted Los Angeles as a new type of city, in contrast to crowded and polluted East coast cities (Deverell and Hise, 2005; Hise and Deverell, 2000) and the backbreaking labor of farming the Midwest (Fogelson 1967). Early city planners placed a low priority on the acquisition of open land because they thought Los Angeles did not require an elaborate municipal parks system (Culver 2010; Deverell and Hise, 2005; Hise and Deverell, 2000). Single-family, bungalow-style homes included their own private yards and gardens, negating the need for public parks (Hise and Deverell, 2000). Furthermore, the prominence of the automobile in Southern California culture allowed families to easily travel to the mountains or beaches for outdoor recreation (Culver 2010). However, this imagined lifestyle of leisure and recreation was not intended for non-Whites. This form of environmental privilege is predicated on the belief that Whites were the "rightful inhabitants" of particular spaces and non-White residents were either excluded from this vision or lacked the means to enjoy it (Culver 2010; Park and Pellow, 2011).

Whiteness itself has been conceptualized as a form of material wealth (Harris 1993) and therefore, as George Lipsitz (2006) argues, Whites have a "possessive investment" in preserving their Whiteness. Whites have gone to great lengths to maintain possession of White spaces and retain their social advantage. Racially restrictive housing covenants, zoning laws, and discriminatory lending practices led to the creation of segregated Latino neighborhoods in Los Angeles. The settlement and displacement of Latinos represent a process called barrioization, whereby Latinos are kept spatially separate from Whites and effectively excluded from larger political, social, and economic aspects of society (Molina 2006; Telles and Ortiz, 2008). The rapid development of Mexican American neighborhoods in Los Angeles can be traced back to industrialization at the turn of the twentieth century when Mexican workers came to fill labor shortages (Acuña 1988). Barrio communities were located East of downtown near the Los Angeles River, as other sections of the city were off limits due to racial segregation (Acuña 1988; Sanchez 1995). When Latino 
migration increased in the 1970s and 1980s due to civil war and political turmoil in Central America, new immigrants settled primarily in industrial and unincorporated areas south of Los Angeles, where they found jobs, affordable housing, and kinship connections (Moore and Vigil, 2000; Waldinger and Bozorgmehr, 1996). Today, Los Angeles remains one of the most segregated regions for Latinos in the United States (Tienda and Fuentes, 2014).

During the mid-twentieth century, economic shifts and rapid population growth led to dramatic changes in the racial geography of the city prompting an exodus among Whites to new suburban communities (Klein 1997; Scott 1998). White flight not only enabled Whites to maintain racially segregated communities, but their exit from the city negatively impacted the local economy, exacerbating the social conditions faced by communities of color (Pulido 2000). Furthermore, Latino (and other non-White) residents of Los Angeles experienced residential displacement (Klein 1997) as a result of development priorities that favored transportation projects over that of the recreational needs of communities of color (Avila 2014; Sanchez 1995). For example, several large-scale urban development projects led to the destruction of parkland used primarily by communities of color (Avila 2014; Deverell and Hise, 2005). The construction of two major freeways, the Golden State Freeway (I-5) and the Pasadena Freeway (I-110) impacted different sections of Elysian Park, located near downtown Los Angeles (Avila 2014; Culver 2010). The portions of the park that were lost were near Chinatown and Latino residential neighborhoods, making it easier for city planners to sacrifice the parkland (Culver 2010). The new freeways cut through non-White neighborhoods in order to enable suburban Whites to live separate from non-Whites but retain access to the rest of the region (Avila 2014). Both suburbanization and transportation infrastructure are examples of White privilege that not only "contributed to contemporary patterns of environmental racism" (Pulido 2000, p. 12) in Los Angeles, but also demonstrate how the benefits that accrue to Whites further disadvantage non-Whites (Park and Pellow, 2011; Pulido 2000).

Another characteristic of White privilege is that it often goes unrecognized (Lipsitz 2006; Pulido 2000). Fiscal discrimination is a race-neutral strategy used to maintain separate leisure spaces for Whites and non-Whites, and to ensure Whites receive greater access to parkland than non-Whites (Culver 2010; Joassart-Marcelli 2010; Joassart-Marcelli et al., 2005; Wolch et al., 2005). In 1978, California voters passed Proposition 13, which reduced property taxes for homeowners and businesses (Pincetl 2003). Despite its popularity among homeowners, Proposition 13 had a devastating effect on parks and other features of civic life. State, county, and city governments drastically cut spending, including the parks budget, which hit poor communities and communities of color especially hard (Culver 2010; Pincetl 2003). However, parks in more affluent areas raised fees and solicited donations from neighborhood residents in order to maintain the programs and facilities (García and White, 2006). In effect, Proposition 13 widened the "recreation gap" between non-White and White neighborhoods (Wolch et al., 2005). In 1996, voters approved Proposition K, which made state funds available for more park space (Wolch et al., 2005). The competitive grant application process favored well-resourced and typically White communities, who were open space proponents, uninterested in developing urban parks in Eastside, largely Latino immigrant neighborhoods (Joassart-Marcelli 2010; Wolch et al., 2005). Jennifer Wolch and colleagues (2005) found that Latino, Black, and Asian American predominant neighborhoods were less successful in acquiring Proposition $\mathrm{K}$ funds compared to White neighborhoods, and concluded that "public policy is structured to intensify, rather than rectify, historic environmental justice problems associated with access to parks and open 
space" (p. 32). Race-neutral policies (Bonilla-Silva 2006; Culver 2010; Delgado and Stefancic, 2012) such as Proposition 13 and Proposition K contribute to the reproduction of White privilege and exacerbate racial inequality in access to parks.

The examples above demonstrate how White privilege reproduces racial inequality in the context of urban environmental spaces (Pulido 2000). Using Los Angeles parks history as a backdrop, we build on existing research about disparities in parks and recreation resources with a focus on Latino immigrant communities. The current study uses recent data from Los Angeles County to examine the relationship between Latino neighborhoods and different types of park features.

\section{DATA}

Data come from two sources, the Los Angeles County Location Management System (LMS) and the American Community Survey (ACS). Both datasets use 2010 Census tract boundaries and all analyses take place at the tract level. The parks and recreation variables come from the LMS, a publicly available database of location information for Los Angeles County (Los Angeles County GIS Data Portal 2013). The dataset includes information on over 66,000 points of interest such as churches, parks, hospitals, and police stations (Greniger 2010). A small subset of relevant LMS parks and recreation data were used for this study. Specifically, the data include information about the type and location of public park features in Los Angeles County, including swimming pools, trails, and beaches. The parks and recreation variables were created using ESRI ArcGIS version 10.0. Tract level sociodemographic data come from the ACS Summary File Estimates.

\section{Variables}

The dependent variable is total park features, a count variable representing the sum of parks and recreation features in a given Census tract. There are ten types of parks and recreation features: beaches or marinas, campgrounds, golf courses, natural areas or wildlife sanctuaries, parks or gardens, picnic areas, pools, recreation centers, recreation programs, and trails. These park features are included because they are commonly used for physical activity, play, and recreation (RWJF 2013). Individual park features are included in the descriptive analyses and the count of total park features measure is used in the regression analysis.

Latino immigrant neighborbood is the main independent variable. A factor score was created to represent Latino immigrant neighborhood features-percent Latino, ${ }^{1}$ percent non-citizen, percent Spanish speaking, and percent foreign born. The factor score was used for several reasons. First, percent Latino alone does not capture other important social features of the Latino immigrant neighborhood context that may relate to park availability (Byrne 2012). For example, residents who speak English and were born in the United States may be more politically active and better able to advocate for park resources than Spanish-speaking, foreign-born residents (Byrne 2012). Second, collinearity checks indicated that the Latino immigrant characteristic variables were highly correlated. The factor score accounts for the relevant immigrant constructs and produces stable estimates in the regression models. The individual variables that comprise the factor score (i.e., percent Latino, non-citizen, Spanish speaking, foreign born) were used in the descriptive analysis and the Latino immigrant neighborhood factor score was used in the regression analysis. The other neighborhood racial composition variables are measured as the percent Black and percent Asian in the tract. 
Percent living in poverty ${ }^{2}$ is included as a control. Poor neighborhoods have fewer resources to build and maintain parks using private funds. Additionally, poor households would be more reliant on free or low-cost parks and recreation programs than households not living in poverty (Dahmann et al., 2010; Sister et al., 2010).

The number of park features in a tract may simply reflect a greater need for more features, rather than have anything to do with race or ethnicity. For example, neighborhoods with more people may require more features to accommodate residents' recreational needs (Moore et al., 2008; Sister et al., 2010; Wolch et al., 2005). Accordingly, we controlled for total population, the number of people per Census tract and population density, the number of people per square mile.

Tracts with limited land area may not have the physical space to accommodate various park features (Sister et al., 2010). The total land area available in a tract, measured as total square miles, may determine whether or not park features are present. Residential land use can also influence park availability because there is less open space in urban areas with high residential density (Duncan et al., 2012; Sister et al., 2010). Apartment buildings and attached housing (e.g., duplex) do not have recreational areas, whereas many detached homes have yards which provide space for play and exercise (Dahmann et al., 2010). Hence, we also controlled for the percent of attached housing (including apartments) in a tract.

\section{ANALYSES}

First, we provided descriptive information on sociodemographic characteristics and park features for Census tracts in Los Angeles. Next, we included bivariate associations to show how those park features are distributed by neighborhood percent Latino. We used multivariable regression analysis to test the association between Latino immigrant neighborhoods and park feature availability. Model 1 tested the association between the racial/ethnic neighborhood composition variables (Latino immigrant neighborhood factor score, percent Black, and percent Asian) and total park features. Model 2 included only neighborhood disadvantage (percent poverty). Model 3 combined the neighborhood composition and neighborhood disadvantage measures. Model 4 added measures of park need (total population and population density) and Model 5 incorporated land variables (land area and attached housing).

The lack of parks in some tracts may arise as a function of spatial size. Accordingly we needed an estimator that can directly model the zeros as a function of land size. Further, preliminary analyses showed high over-dispersion and model selection tests (e.g., the likelihood-ratio test of alpha and the Vuong test) confirmed a Poisson model was insufficient for modeling our count data (Atkins and Gallop, 2007). We employed the zero-inflated negative binomial model (ZINB) to account for the distribution of our outcome variable.

\section{RESULTS}

\section{Los Angeles County Tract Sociodemographic Information}

Table 1 shows the sociodemographic information for all Census tracts in the sample $(n=2315)$. Latinos (47\%) comprise the largest racial/ethnic group in Los Angeles County, followed by Whites (29\%), Asians (13\%), Blacks (8\%), and other (2\%). Forty percent of Los Angeles County residents speak Spanish at home, over a third are foreign born, and $20 \%$ are not U.S. citizens. Sixteen percent of households live below 
Table 1. Sociodemographic Statistics for Sample of Los Angeles County Census Tracts $(n=2315)$

\begin{tabular}{lrr}
\hline \hline Variable & Mean & \multicolumn{1}{c}{ SD } \\
\hline NEIGHBORHOOD RACIAL/ETHNIC COMPOSITION & & \\
\% Latino & 0.47 & 0.30 \\
\% White & 0.29 & 0.27 \\
\% Black & 0.08 & 0.14 \\
\% Asian & 0.13 & 0.16 \\
\% Other & 0.02 & 0.02 \\
IMMIGRANT RELATED FACTORS & & \\
\% Spanish Speaking & 0.40 & 0.29 \\
\% Foreign Born & 0.36 & 0.15 \\
\% Non-citizen & 0.20 & 0.13 \\
NEIGHBORHOOD DISADVANTAGE & & \\
\% Households in Poverty & 0.16 & 0.12 \\
POPULATION & & \\
Total Population & 4205.07 & 1443.39 \\
Population Density (per sq. mile) & $13,237.88$ & $11,170.97$ \\
LAND & & \\
Land Area (sq. miles) & 1.69 & 13.11 \\
\% Attached Housing & 0.45 & 0.30 \\
\hline
\end{tabular}

Source: American Community Survey, 2006-2010.

the Federal Poverty Line. The mean total population is 4205 residents per tract, and Los Angeles County is densely populated with over 13,000 people per square mile on average. The mean tract size is 1.69 square miles, and the mean percent of attached housing in Los Angeles is $45 \%$. Table 2 reports sociodemographic statistics by Latino quartile and shows that neighborhoods with a high percentage of Latino residents also have the highest poverty rate and are twice as dense as neighborhoods in the very low Latino quartile.

\section{Park Features in Los Angeles County}

Table 3 shows the distribution for detailed park features for all tracts in the sample. The mean number of total park features per tract is 1.07 and the large range (0-152) indicates that there were many tracts containing zero park features and one tract with 152 park features. Recall that there are a variety of park features, so this is not interpreted as 152 stand-alone parks. Parks and gardens represent the most common category of park features with a mean of 0.54 per tract. The next most common park features in Los Angeles County were campgrounds (0.12), recreation centers (0.11), and recreation programs (0.09). Finally, the remaining park feature categories are natural areas $(0.04)$, golf courses (0.04), pools (0.03), beaches (0.03), trails (0.03), and picnic areas (0.02).

Table 4 presents the distribution of park features by Latino quartile. There is a clear pattern of park availability across Census tracts-as the proportion of Latino residents in the neighborhood increases, the mean number of total park features decreases. This finding provides preliminary support for the hypothesis that Latino neighborhoods will have fewer park features than non-Latino neighborhoods. The high percent Latino 
Jennifer J. García et al.

Table 2. Tract Sociodemographic Statistics by Latino Quartile $(n=2315)$

\begin{tabular}{lrrrr}
\hline \hline & $\begin{array}{c}\text { Very Low } \\
\text { Latino }\end{array}$ & $\begin{array}{c}\text { Low } \\
\text { Latino }\end{array}$ & $\begin{array}{c}\text { Medium } \\
\text { Latino }\end{array}$ & \multicolumn{1}{c}{$\begin{array}{c}\text { High } \\
\text { Latino }\end{array}$} \\
\hline $\begin{array}{l}\text { NEIGHBORHOOD RACIAL/ETHNIC } \\
\text { COMPOSITION }\end{array}$ & & & & \\
\% Latino & 0.10 & 0.30 & 0.59 & 0.87 \\
\% White & 0.61 & 0.36 & 0.16 & 0.04 \\
\% Black & 0.07 & 0.10 & 0.12 & 0.04 \\
\% Asian & 0.18 & 0.20 & 0.11 & 0.04 \\
\% Other & 0.03 & 0.03 & 0.02 & 0.01 \\
IMMIGRANT RELATED FACTORS & & & & \\
\% Spanish Speaking & 0.07 & 0.22 & 0.50 & 0.78 \\
\% Foreign Born & 0.27 & 0.32 & 0.38 & 0.46 \\
\% Non-citizen & 0.10 & 0.14 & 0.23 & 0.32 \\
NEIGHBORHOOD DISADVANTAGE & & & & \\
\% Households in Poverty & 0.09 & 0.12 & 0.19 & 0.24 \\
POPULATION & & & & \\
Total Population & 4040.60 & 4170.34 & 4398.70 & 4209.97 \\
Population Density (per sq. mile) & 9242.50 & $10,661.30$ & $14,993.70$ & $18,019.20$ \\
LAND & & & & \\
Land Area (sq. miles) & & & & \\
\% Attached Housing & 1.89 & 3.33 & 1.15 & 0.41 \\
& 0.44 & 0.42 & 0.48 & 0.46 \\
\hline \hline
\end{tabular}

Source: American Community Survey, 2006-2010.

tracts have a mean of 0.65 total park features per tract, whereas the tracts with the lowest percent Latino have 1.54 park features per tract. High percent Latino neighborhoods have no campgrounds, trails, beaches, or picnic areas. Recreation centers and recreation programs appear to be evenly distributed across Latino quartiles.

Table 3. Detailed Park Features for Sample of Los Angeles County Census Tracts $(n=2315)$

\begin{tabular}{lcccr}
\hline \hline Variable & Mean & SD & Min & Max \\
\hline Beaches or Marinas & 0.03 & 0.76 & 0 & 34 \\
Campgrounds & 0.12 & 2.11 & 0 & 90 \\
Golf Courses & 0.04 & 0.21 & 0 & 3 \\
Natural Areas or Wildlife Sanctuaries & 0.04 & 0.51 & 0 & 16 \\
Parks and Gardens & 0.54 & 0.91 & 0 & 11 \\
Picnic Areas & 0.02 & 0.37 & 0 & 12 \\
Recreation Centers & 0.11 & 0.37 & 0 & 3 \\
Recreation Programs & 0.09 & 0.33 & 0 & 3 \\
Swimming Pools & 0.03 & 0.21 & 0 & 6 \\
Trails & 0.03 & 0.52 & 0 & 16 \\
Total Park Features & 1.07 & 4.21 & 0 & 152 \\
\hline
\end{tabular}

Source: American Community Survey, 2006-2010. 
Table 4. Mean Number of Park Features per Tract by Latino Quartile $(n=2315)$

\begin{tabular}{lcccc}
\hline \hline & Very Low Latino & Low Latino & Medium Latino & High Latino \\
\hline Beaches or Marinas & 0.11 & 0.01 & 0.01 & 0 \\
Campgrounds & 0.15 & 0.28 & 0.03 & 0 \\
Golf Courses & 0.09 & 0.03 & 0.02 & 0.02 \\
Natural Areas or Wildlife & 0.07 & 0.07 & 0.03 & 0.01 \\
$\quad$ Sanctuaries & 0.76 & 0.58 & 0.44 & 0.37 \\
Parks and Gardens & 0.05 & 0.04 & 0 & 0 \\
Picnic Areas & 0.11 & 0.10 & 0.11 & 0.13 \\
Recreation Centers & 0.10 & 0.10 & 0.08 & 0.07 \\
Recreation Programs & 0.03 & 0.02 & 0.03 & 0.04 \\
Swimming Pools & 0.03 & 0.06 & 0.01 & 0 \\
Trails & 1.54 & 1.34 & 0.77 & 0.65 \\
Total Park Features & & & & \\
\hline \hline
\end{tabular}

Source: Location Management System, 2010.

\section{Availability of Park Features in Latino Immigrant Neighborhoods}

The ZINB regression results from both the logistic and the negative binomial portions of the model are presented in Table 5. The logistic or zero portion of the model, presented in the top panel (Table 5), shows a significant negative relationship between total land area and zero counts. Hence, smaller sized tracts are more likely to have no parks, which support our assertion that limited land area might explain the excess zeros in the data.

The results from the negative binomial portion of the model, presented in the bottom panel (Table 5), support our hypothesis that Latino immigrant neighborhoods will have limited availability of total park features. Model 1 shows that Latino immigrant neighborhood factor score, percent Black, and percent Asian have significant negative relationships with the total number of park features in the neighborhood. Model 2 tested the bivariate association between percent poverty and total park features, in order to isolate the effect of neighborhood disadvantage on park availability. Results show that greater poverty was associated with fewer park features. However, when poverty and the neighborhood composition variables from Model 1 were included in the same model (Model 3), the association between poverty and parks became positive.

Model 4 introduces total population and population density, which both had very small effects. Although total population was not significant in this model, population density accounts for some of the relationship between Latino immigrant neighborhoods and number of park features because the Latino immigrant neighborhood factor score decreases, but remains statistically significant.

Model 5 introduces the variables that proxy for park need. Contrary to our expectations, the percent of attached housing was associated with more park features in the tract. The negative association between the neighborhood racial composition variables and park features remains, but percent Asian becomes non-significant. Interestingly, total population is now significant. Also, the coefficient for percent living in poverty decreased between Models 4 and 5, indicating that some of the effect of poverty was captured by the inclusion of the land variables in the model. Although the Latino immigrant neighborhood factor score coefficient decreased from - 0.41 (Model 1) to -0.15 (Model 5), it remains statistically significant. 
Table 5. Results of Zero-Inflated Negative Binomial Regression (ZINB) Analysis for Total Park Features

\begin{tabular}{|c|c|c|c|c|c|}
\hline & Model 1 & Model 2 & Model 3 & Model 4 & Model 5 \\
\hline Land Area (sq. miles) & $-7.39^{* * *}(1.24)$ & $-7.61^{* * *}(1.08)$ & $-7.73^{* * *}(1.27)$ & $-5.15^{\star * *}(1.50)$ & $-5.04^{* * *}(1.18)$ \\
\hline \multicolumn{6}{|l|}{ Negative binomial model (Count portion) } \\
\hline Latino Immigrant Neighborhood Factor Score & $-0.41^{\star * *}(0.04)$ & & $-0.51^{* * *}(0.05)$ & $-0.31^{\star * *}(0.05)$ & $-0.15^{\star * *}(0.05)$ \\
\hline$\%$ Black & $-0.97^{* * *}(0.28)$ & & $-1.25^{* * *}(0.29)$ & $-0.95^{* * *}(0.28)$ & $-0.51^{*}(0.25)$ \\
\hline Total Population & & & & $0.00(0.00)$ & $0.00^{\star * *}(0.00)$ \\
\hline Population Density (per sq. mile) & & & & $-0.00^{* * *}(0.00)$ & $-0.00^{* * *}(0.00)$ \\
\hline Land Area (sq. miles) & & & & & $0.02^{\text {*** }}(0.00)$ \\
\hline$\%$ Attached Housing & & & & & $0.87^{* * *}(0.13)$ \\
\hline Constant & $0.42^{* * *}(0.06)$ & $0.46^{* * *}(0.06)$ & $0.21^{* *}(0.08)$ & $0.52^{* * *}(0.12)$ & $-0.30^{*}(0.13)$ \\
\hline
\end{tabular}

Standard errors in parentheses

${ }^{*} p<0.05,{ }^{* *} p<0.01,{ }^{* * *} p<0.001$ 
Table 6 shows that as Latino immigrant neighborhood factor score increases, the corresponding count of total park features drops. Specifically, neighborhoods with few Latino immigrant neighborhood features (i.e., low percent Latino, low non-citizen, low Spanish speaking, and low foreign born) had 6.77 park features per tract whereas neighborhoods with a high Latino immigrant neighborhood factor score (i.e., had high percentages of all these variables) had only 3.66 park features per tract.

\section{CONCLUSION}

Prior work has shown that the availability of health-promoting parks and recreation resources vary by neighborhood racial/ethnic composition (Abercrombie et al., 2008; Dahmann et al., 2010; Duncan et al., 2012; Sister et al., 2010; Wolch et al., 2005). An important but often overlooked aspect of these disparities in the built environment is the historical context in which they evolved and their connection to White privilege (Chowkwanyun 2011; Pulido 2000). The goal of this article was to apply a CRT lens to enhance the study of race and the environment. Our strategy was twofold: first, provide appropriate social and historical background for our examination of racialized park disparities; and second, test the relationship between Latino immigrant neighborhoods and the availability of park features using recent data from Los Angeles.

A unique contribution of this study is our use of a CRT framework to highlight how race and racism shape urban development. Our historical overview of Latino neighborhoods and park planning in Los Angeles illustrates how the proximity of White neighborhoods to resources such as parks and beaches did not occur by chance. Viewed through the lens of White privilege, city planners, politicians, and White residents intentionally excluded people of color from parks, playgrounds, and neighborhoods through various means (e.g., de facto segregation, zoning laws, and fiscal discrimination) in order to preserve their power and wealth. This complex and important history is rarely discussed when examining the relationship between the built environment and racial disparities in health (Chowkwanyun 2011). We have focused on White privilege in our examination of race and the environment, but other features of a racialized society studied by CRT scholars, such as intersectionality and interest convergence, are also important avenues of scholarly inquiry. In addition, CRT methods such as revisionist interpretations of history and counter-storytelling can provide fresh perspectives and additional insights about the actors and social forces at play in creating environmental inequity (Taylor 2009).

Table 6. Predicted Counts of Total Park Features for Each Level of Latino Immigrant Neighborhood Factor Score

\begin{tabular}{lc}
\hline $\begin{array}{l}\text { Latino Immigrant Neighborhood } \\
\text { Factor Score }\end{array}$ & $\begin{array}{c}\text { Predicted Count of Total Park Features } \\
\text { per Tract }\end{array}$ \\
\hline-2 & 6.77 \\
-1 & 5.81 \\
0 & 4.98 \\
1 & 4.27 \\
2 & 3.66
\end{tabular}

Note: Increasing factor score means more Latino immigrant neighborhood features (i.e., high percent Latino, non-citizen, Spanish speaking, and foreign born residents). Predicted counts are based on Model 5 (Table 5) parameter estimates. 
Results from the bivariate analysis of detailed park features show patterns that are consistent with the racialized history of Los Angeles urban park development (Byrne and Wolch, 2009; Culver 2010). Neighborhoods with a very low percentage of Latino residents had over twice as many total park features compared to highly concentrated Latino neighborhoods. Among the most heavily concentrated Latino neighborhoods, there were no beaches or marinas, campgrounds, trails, or picnic areas. However, recreation centers and recreation programs, neither of which requires open space or vast parkland (Dahmann et al., 2010), were more evenly distributed across neighborhoods. These patterns are consistent with the racial geography of Los Angeles-Latino concentrated neighborhoods are located in the Eastern and Southern parts of Los Angeles (Moore and Vigil, 2000), far from the beaches and marinas on the predominantly White, West side of town (Culver 2010). These findings, while not surprising given the legacy of residential segregation, remind us that the history and impact of discriminatory planning practices should be taken into consideration when trying to account for current racial/ethnic differences in park usage, determining allocation of resources, and especially when planning future park development projects to ensure a more equitable urban park landscape.

Our findings from the regression analysis extend previous work that shows communities of color in Los Angeles have limited access to park resources (Dahmann et al., 2010; Sister et al., 2010; Wolch et al., 2005). We focus on Latino immigrant neighborhoods specifically because historical processes of barrioization suggest that Latino immigrant neighborhoods are disenfranchised with respect to environmental and recreational resources (Boone et al., 2009; Johnson-Gaither 2011). We find that neighborhoods with more Latino immigrant characteristics were associated with fewer total park features. Our findings suggest that Latino immigrant communities in Los Angeles are "park poor" and may be missing out on opportunities for recreation and physical activity that support healthy lifestyles (Moore et al., 2008). As our data show, many tracts are densely populated without adequate land area to build new parks. Therefore, an equitable park development plan should include maintenance and improvement of existing parks and programs, creative use of alternative resources (e.g., school yards), and reliable and affordable transportation to access environmental resources in other parts of the city (García and Flores, 2005; Sister et al., 2010).

Our study has some limitations. Our interpretation of the data assumes more park features is better, but our total park features measure does not account for the quality of the park features. Questions related to the age, size, and condition of park features would be interesting avenues for future inquiry on disparities in park resources. An additional limitation of the current analysis is reliance on Census tracts to represent neighborhoods. In this study neighborhoods are treated as distinct entities, but Census tracts are arbitrary boundaries that residents regularly cross (Reardon 2006). Future work should consider the use of buffer zones (i.e., within a certain square mile radius) which might temper our findings of a negative association between Latino immigrant neighborhood characteristics and number of park features. Finally, due to the crosssectional nature of this study, we cannot establish a causal relationship between neighborhood racial/ethnic composition and park features. Nevertheless, our inclusion of rich historical background reminds us that parks, like neighborhoods, were developed as racialized projects and can be thought of as spatial expressions of racial discrimination (Boone et al., 2009; Byrne and Wolch, 2009).

Using a CRT framework, the current study examined White privilege within a historicized analysis in order advance our understanding about race and the environment 
and their consequences for health. In general, public health scholarship can benefit from the study of historical racism in order to better understand the root causes of present day racialized health inequities.

Corresponding author: Jennifer J. García, Division of Health Sciences, California State University, Dominguez Hills, 1000 E. Victoria Street, Welch Hall A330-L, Carson, CA 90747. E-mail: jjgarcia@ csudh.edu

\section{NOTES}

1. Latino includes all races that checked Hispanic/Latino ethnicity on the ACS, and the remaining groups are all "non-Hispanic/Latino." For the purposes of this paper, we have defined race/ethnicity such that Hispanic/Latino ethnicity trumps race. We used the term race/ethnicity because the racial/ethnic categories can include both racial and/or ethnic identities.

2. Poverty is measured as percent of the population whose income falls below the poverty threshold. According to the Census Bureau, the poverty threshold is defined as "money income before taxes and does not include capital gains or noncash benefits (such as public housing, Medicaid, and food stamps)" and varies by family size and composition (U.S. Census Bureau 2010).

\section{REFERENCES}

Abercrombie, Lauren C., James F. Sallis, Terry L. Conway, Lawrence D. Frank, Brian E. Saelens, and James E. Chapman (2008). Income and Racial Disparities in Access to Public Parks and Private Recreation Facilities. American fournal of Preventive Medicine, 34(1): 9-15.

Acuña, Rodolfo (1988). Occupied America: A History of Chicanos. Third edition. New York: Harper \& Row.

Atkins, David C., and Robert J. Gallop (2007). Rethinking How Family Researchers Model Infrequent Outcomes: A Tutorial on Count Regression and Zero-Inflated Models. Fournal of Family Psychology, 21(4): 726.

Avila, Eric (2014). The Folklore of the Freeway: Race and Revolt in the Modernist City. Minneapolis, MN: University of Minnesota Press.

Bonilla-Silva, Eduardo (1997). Rethinking Racism: Toward a Structural Interpretation. American Sociological Review, 62(3): 465-480.

Bonilla-Silva, Eduardo (2006). Racism without Racists: Color-Blind Racism and the Persistence of Racial Inequality in the United States. Lanham, MD: Rowman \& Littlefield Publishers.

Boone, Christopher G., Geoffrey L. Buckley, J. Morgan Grove, and Chona Sister (2009). Parks and People: An Environmental Justice Inquiry in Baltimore, Maryland. Annals of the Association of American Geographers, 99(4): 767-787.

Byrne, Jason (2012). When Green Is White: The Cultural Politics of Race, Nature and Social Exclusion in a Los Angeles Urban National Park. Geoforum, 43(3): 595-611.

Byrne, Jason, and Jennifer Wolch (2009). Nature, Race, and Parks: Past Research and Future Directions for Geographic Research. Progress in Human Geography, 33(6): 743-765.

Chowkwanyun, Merlin (2011). The Strange Disappearance of History from Racial Health Disparities Research. Du Bois Review: Social Science Research on Race, 8(01): 253-270.

Corral, Irma, Hope Landrine, and Luhua Zhao (2014). Residential Segregation and Obesity among a National Sample of Hispanic Adults. Fournal of Health Psychology, 19(04): 503-508.

Crenshaw, Kimberlé (1995). Critical Race Theory: The Key Writings That Formed the Movement. New York: The New Press.

Culver, Lawrence (2010). America's Playground: Recreation and Race. In William Deverell and Greg Hise (Eds.), A Companion to Los Angeles, pp. 421-437. West Sussex, UK: Wiley-Blackwell.

Dahmann, Nicholas, Jennifer Wolch, Pascale Joassart-Marcelli, Kim Reynolds, and Michael Jerrett (2010). The Active City? Disparities in Provision of Urban Public Recreation Resources. Health \& Place, 16(3): 431-445.

Day, Kristen (2006). Active Living and Social Justice: Planning for Physical Activity in Low-Income, Black, and Latino Communities. Fournal of the American Planning Association, 72(1): 88-99.

Delgado, Richard, and Jean Stefancic (2000). Critical Race Theory: The Cutting Edge. Philadelphia, PA: Temple University Press. 
Delgado, Richard, and Jean Stefancic (2012). Critical Race Theory: An Introduction. New York: NYU Press.

Deverell, William, and Greg Hise (2005). Land of Sunshine: An Environmental History of Metropolitan Los Angeles. Pittsburgh, PA: University of Pittsburgh Press.

Do, D. Phuong, Tamara Dubowitz, Chloe E. Bird, Nicole Lurie, José J. Escarce, and Brian K. Finch (2007). Neighborhood Context and Ethnicity Differences in Body Mass Index: A Multilevel Analysis Using the Nhanes III Survey (1988-1994). Economics \& Human Biology, 5(2): 179-203.

Duncan, Dustin T., Ichiro Kawachi, Kellee White, and David R. Williams (2013). The Geography of Recreational Open Space: Influence of Neighborhood Racial Composition and Neighborhood Poverty. Fournal of Urban Health, 90(4): 618-631.

Fogelson, Robert M. (1967). The Fragmented Metropolis: Los Angeles, 1850-1930. Cambridge, MA: Harvard University Press.

Ford, Chandra L., and Collins O. Airhihenbuwa (2010). The Public Health Critical Race Methodology: Praxis for Antiracism Research. Social Science \& Medicine, 71(8): 1390-1398.

García, Robert, and Erica S. Flores (2005). Anatomy of the Urban Parks Movement: Equal Justice, Democracy, and Livability in Los Angeles. In Robert D. Bullard (Ed.), The Quest for Environmental fustice: Human Rights and the Politics of Pollution, pp. 145-167. San Francisco, CA: Sierra Club Books.

García, Robert, and Aubrey White (2006). Healthy Parks, Schools, and Communities: Mapping Green Access and Equity for the Los Angeles Region. The City Project Policy Report. <https://www. cityprojectca.org/publications/documents/Healthy_Parks_Schools_Communities_textonly. pdf> (accessed May 29, 2007).

Gee, Gilbert C., and Devon C. Payne-Sturges (2004). Environmental Health Disparities: A Framework Integrating Psychosocial and Environmental Concepts. Environmental Health Perspectives, 112(17): 1645.

Graham, Louis, Shelly Brown-Jeffy, Robert Aronson, and Charles Stephens (2011). Critical Race Theory as Theoretical Framework and Analysis Tool for Population Health Research. Critical Public Health, 21(1): 81-93.

Greniger, Mark (2010). Los Angeles County Location Management System. Los Angeles County Enterprise GIS.

Harnik, P., R. Donahue, and L. Weiswerda (2012). 2012 City Park Facts. Edited by The Trust for Public Land. <https://www.tpl.org/2012-city-park-facts-report-0> (accessed August 10, 2016).

Harris, Cheryl I. (1993). Whiteness as Property. Harvard Law Review, 106(8): 1707-1791.

Hise, Greg, and William Francis Deverell (2000). Eden by Design: The 1930 Olmsted-Bartholomew Plan for the Los Angeles Region. Berkeley, CA: University of California Press.

Joassart-Marcelli, Pascale (2010). Leveling the Playing Field? Urban Disparities in Funding for Local Parks and Recreation in the Los Angeles Region. Environment and Planning, 42(5): 1174.

Joassart-Marcelli, Pascale M., Juliet A. Musso, and Jennifer R. Wolch (2005). Fiscal Consequences of Concentrated Poverty in a Metropolitan Region. Annals of the Association of American Geographers, 95(2): 336-356.

Johnson-Gaither, Cassandra (2011). Latino Park Access: Examining Environmental Equity in a New Destination County in the South. Fournal of Park and Recreation Administration, 29(4): 37-52.

Klein, Norman M. (1997). The History of Forgetting: Los Angeles and the Erasure of Memory. London: Verso.

Lipsitz, George (2006). The Possessive Investment in Whiteness: How White People Profit from Identity Politics. Philadelphia, PA: Temple University Press.

Los Angeles County GIS Data Portal. 2013. Location/Points of Interest (LMS Data).

Molina, N. (2006). Fit to Be Citizens?: Public Health and Race in Los Angeles, 1879-1939. Berkeley, CA: University of California Press.

Moore, Joan, and James Diego Vigil (2000). Barrios in Transition. In Peter Kivisto and Georganne Rundblad (Eds.), Multiculturalism in the United States: Current Issues, Contemporary Voices, pp. 355-369. Thousand Oaks, CA: Pine Forge Press.

Moore, Latetia V., Ana V. Diez Roux, Kelly R. Evenson, Aileen P. McGinn, and Shannon J. Brines (2008). Availability of Recreational Resources in Minority and Low Socioeconomic Status Areas. American fournal of Preventive Medicine, 34(1): 16-22.

Park, Lisa Sun-Hee, and David N. Pellow (2011). The Slums of Aspen: Immigrants vs. the Environment in America's Eden. New York: NYU Press.

Park, Yoosun, Kathryn Neckerman, James Quinn, Christopher Weiss, and Andrew Rundle (2008). Place of Birth, Duration of Residence, Neighborhood Immigrant Composition and 
Body Mass Index in New York City. International fournal of Behavioral Nutrition and Physical Activity, 5(1): 19.

Pincetl, Stephanie (2003). Nonprofits and Park Provision in Los Angeles: An Exploration of the Rise of Governance Approaches to the Provision of Local Services. Social Science Quarterly, 84(4): 979-1001.

Pulido, Laura (2000). Rethinking Environmental Racism: White Privilege and Urban Development in Southern California. Annals of the Association of American Geographers, 90(1): 12-40.

Reardon, Sean F. (2006). A Conceptual Framework for Measuring Segregation and Its Association with Population Outcomes. In J. Michael Oakes and Jay S. Kaufman (Eds.), Methods in Social Epidemiology, pp. 169-192. San Francisco, CA: Jossey-Bass.

Robert Wood Johnson Foundation (RWJF) (2013). Active Living Resources for Parks \& Recreation. Active Living Research. <http://activelivingresearch.org/taxonomy/parks-recreation> (accessed June 27, 2013).

Sallis, James F., and Karen Glanz (2009). Physical Activity and Food Environments: Solutions to the Obesity Epidemic. Milbank Quarterly, 87(1): 123-154.

Sanchez, George J. (1995). Becoming Mexican American: Ethnicity, Culture, and Identity in Chicano Los Angeles, 1900-1945. New York: Oxford University Press.

Scott, Allen J. (1998). The City: Los Angeles and Urban Theory at the End of the Twentieth Century. Berkeley, CA: University of California Press.

Sister, Chona, Jennifer Wolch, and John Wilson (2010). Got Green? Addressing Environmental Justice in Park Provision. Geofournal, 75(3): 229-248.

Taylor, Dorceta E. (2009). The Environment and the People in American Cities, 1600s1900s: Disorder, Inequality, and Social Change. Durham, NC: Duke University Press.

Telles, Edward M., and Vilma Ortiz (2008). Generations of Exclusion: Mexican-Americans, Assimilation, and Race. New York: Russell Sage Foundation.

Tienda, Marta, and Norma Fuentes (2014). Hispanics in Metropolitan America: New Realities and Old Debates. Annual Review of Sociology, 40: 499-520.

U.S. Census Bureau. 2010. Geographic Terms and Concepts-Census Tract. Geography. <http:// www.census.gov/geo/reference/gtc/gtc_ct.html> (accessed June 27, 2013).

Waldinger, Roger David, and Mehdi Bozorgmehr (1996). Ethnic Los Angeles. New York: Russell Sage Foundation.

Wen, Ming, and Thomas N. Maloney (2011). Latino Residential Isolation and the Risk of Obesity in Utah: The Role of Neighborhood Socioeconomic, Built-Environmental, and Subcultual Context. Fournal of Immigrant Minority Health, 13(6): 1134-1141.

White, Kellee (2011). The Sustaining Relevance of W. E. B. Du Bois to Health Disparities Research. Du Bois Review: Social Science Research on Race, 8(1): 285-293.

Williams, D. R., and C. Collins (2001). Racial Residential Segregation: A Fundamental Cause of Racial Disparities in Health. Public Health Reports, 116(5): 404.

Wolch, Jennifer, John P. Wilson, and Jed Fehrenbach (2005). Parks and Park Funding in Los Angeles: An Equity-Mapping Analysis. Urban Geography, 26(1): 4-35. 